\title{
Severe asthma and ARDS triggered by acute short-term exposure to commonly used cleaning detergents
}

\author{
C.E. Mapp*, V. Pozzato*, V. Pavoni**, G. Gritti**
}

Severe asthma and ARDS triggered by acute short-term exposure to commonly used cleaning detergents. C.E. Mapp, V. Pozzato, V. Pavoni, G. Gritti (C)ERS Journals Ltd 2000. ABSTRACT: This report presents a case of severe asthmatic attack and adult respiratory distress syndrome, which occurred in an asthmatic subject following acute short-term exposure to commonly used cleaning detergents. Premorbid lung conditions, i.e. asthma and airway hyperresponsiveness, might have been risk factors for illness severity but not for persistent complaints.

This case report indicates that nonindustrial exposures due to household product misuse, especially to mixing cleaning agents, may cause adult respiratory distress syndrome and not only irritant-induced asthma.

Eur Respir J 2000; 16: 570-572.
*Dept. of Environmental Medicine and Public Health, University of Padua, and **Intensive Care Unit, University Hospital, Padua, Italy.

Correspondence: C.E. Mapp, Dipartimento di Medicina Ambientale e Sanita Pubblica Via Giustiniani 235128 Padova, Italy. Fax: 390498212566

Keywords: Acids, adult respiratory distress syndrome, asthma, chlorine, cleaning detergents, inhalation

Received: November 251999

Accepted after revision May 222000

This study was supported by Ministero dell' Universita' e della Ricerca Scientifica e Technologica $(60 \%$ and $40 \%)$ and Associazione per la Ricerca e la Curadell' Asma.
A 22-yr old female, who had never smoked, was referred to the University Hospital, Padua, in June 1999 because of respiratory symptoms in the workplace. She was employed as a cleaner in a chain of cafeterias. A few minutes after mixing bleach (sodium hypochlorite, $4.9 \%$ ) and a detergent containing malic acid $(10 \%)$ and sulphamic acid $(2 \%)$, used to remove limescale from a shower stall located in the changing room, she complained of a burning sensation in her throat and wheezing. From this mixture, chlorine vapours had arisen [1]. She had turned on the hot water tap and left the room. After $5 \mathrm{~min}$, she had gone back into the room to turn off the tap and immediately afterwards walked out of the room. Then, she had inhaled $200 \mu \mathrm{g}$ salbutamol and gone by car she went to work in another cafeteria. When she arrived 20 min later, she complained of a dry cough, breathlessness and chest tightness.

While she was being taken to hospital by ambulance, she was treated with oxygen, salbutamol and glucocorticoids. When she arrived in the emergency room, she was increasingly dyspnoeic and tachypnoeic ( 38 breaths $\cdot \min ^{-1}$ ) and her pulse was 140 beats. $\mathrm{min}^{-1}$. Her arterial oxygen tension $\left(\mathrm{Pa}, \mathrm{O}_{2}\right)$ was $\left(7.6 \mathrm{kPa}(57 \mathrm{mmHg}), \mathrm{Pa}_{2} \mathrm{CO}_{2}\right) 4.5 \mathrm{kPa}$ $(33.9 \mathrm{mmHg})$ and arterial oxygen saturation $\left(\mathrm{Sa}_{2} \mathrm{O}_{2}\right) 90.5 \%$. Auscultation of the chest revealed diffuse bronchospasm. Treatment with $100 \%$ oxygen $\left(6 \mathrm{~L} \cdot \mathrm{min}^{-1}\right)$, methylprednisolone, adrenalin, salbutamol, ipratropium bromide, magnesium sulphate and aminophylline was started. Twelve hours later her $\mathrm{Sa}_{\mathrm{a}} \mathrm{O}_{2}$ had fallen from 90.5 to $83 \%$. She was admitted to the intensive care unit (ICU), where continuous positive airway pressure was initiated via an occlusive face mask. The ratio $\mathrm{Pa}_{\mathrm{a}} \mathrm{O}_{2} /$ inspiratory oxygen fraction $\left(F \mathrm{I}, \mathrm{O}_{2}\right)$ was 95. The following day, her condition worsened (respirations frequency was 50 breaths $\cdot \mathrm{min}^{-1}$ ). A chest radiograph obtained $42 \mathrm{~h}$ after chlorine inhalation showed a worsening of the radiographic features observed a few hours after exposure, with progression of alveolar infiltrates, which were most marked on the right, in the middle and lower lung zones (fig. 1a and 1b). In the afternoon, after sedation, she was intubated and mechanical ventilatory support (pressure-controlled ventilation) with a positive end-expiratory pressure (PEEP) of $10 \mathrm{cmH}_{2} \mathrm{O}$ had to be started. The pressure support was $30 \mathrm{cmH}_{2} \mathrm{O}$, mean airways pressure $14 \mathrm{cmH}_{2} \mathrm{O}$ and central venous pressure (CVP) $7 \mathrm{mmHg}$. One hour after intubation, $\mathrm{Pa}_{\mathrm{a}} \mathrm{O}_{2}$ was $11.7 \mathrm{kPa}(88 \mathrm{mmHg}), F \mathrm{I}, \mathrm{O}_{2} 80 \%$ and $P \mathrm{a}_{2} \mathrm{O}_{2} / F \mathrm{I}, \mathrm{O}_{2}$ ratio 110. To improve alveolar recruitment and oxygenation, prone positioning was adopted. The following day the $P \mathrm{a}, \mathrm{O}_{2} / F \mathrm{I}, \mathrm{O}_{2}$ was 241 , but hypercapnia appeared $\left(\mathrm{Pa}_{\mathrm{a}}, \mathrm{CO}_{2}\right.$ $6.8 \mathrm{kPa}(51.3 \mathrm{mmHg}))$. Antibiotics, anticoagulants and dopamine were added to the treatment.

The following day, auscultation of the chest revealed diffuse bronchospasm and the $\mathrm{Pa}, \mathrm{O}_{2} / F \mathrm{I}, \mathrm{O}_{2}$ was 258 . One day later, bronchospasm lessened, $\mathrm{Sa}_{\mathrm{a}} \mathrm{O}_{2}$ was $96 \%$, PEEP was $6 \mathrm{cmH}_{2} \mathrm{O}$ and the $\mathrm{Pa}, \mathrm{O}_{2} / F \mathrm{I}, \mathrm{O}_{2}$ ratio was 200 . Twentyfour hours later, her condition worsened further: auscultation of the chest revealed both crackles and rales and fever appeared. The chest radiograph showed increased oedema and an $\mathrm{Pa}, \mathrm{O}_{2} / F \mathrm{I}, \mathrm{O}_{2}$ ratio of 198 . In the following 3 days, she improved slowly and sedative doses were reduced. PEEP 

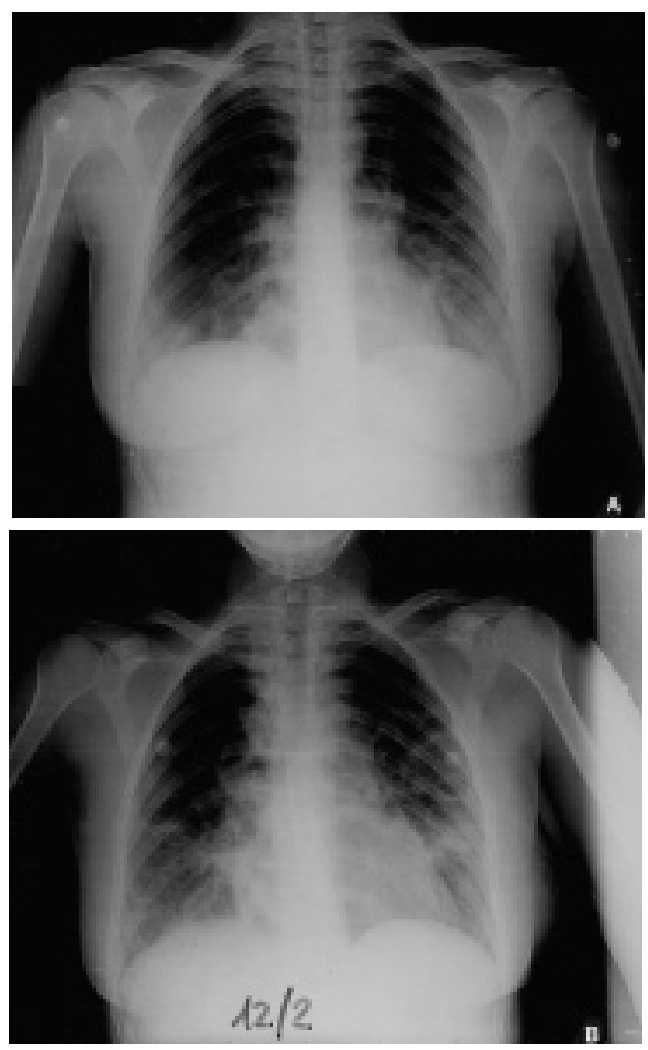

Fig. 1. - Chest radiographs obtained from the patient: a) $9 \mathrm{~h}$; and b) $42 \mathrm{~h}$ after chlorine inhalation. a) Diffuse and bilateral alveolar infiltrates. Note normal heart size. b) Progression of alveolar infiltrates, most marked on the right in the middle and lower lung zones.

was also reduced to $5 \mathrm{cmH}_{2} \mathrm{O}$. The $P \mathrm{a}, \mathrm{O}_{2} / F \mathrm{I}, \mathrm{O}_{2}$ ratios were, respectively, 240, 242 and 350 .

On the afternoon of the following day after sedatives were stopped, a successful extubation was performed. The $P \mathrm{a}, \mathrm{O}_{2} / F \mathrm{I}, \mathrm{O}_{2}$ ratio was 380 . The chest radiograph showed reduced infiltrates, the respiratory frequency was reduced $\left(27\right.$ breaths $\left.\cdot \mathrm{min}^{-1}\right)$ and auscultation of the chest revealed the absence of bronchospasm. Her fever disappeared. The dosage of glucocorticoids was reduced and aminophylline was stopped. Three days after extubation, she was transferred to the Dept of Environmental Medicine and Public Health section of Occupational Medicine and discharged 11 days later. Three months after the acute exposure to chlorine, she was asymptomatic, clinical examination gave normal results and respiratory parameters were as follows: forced vital capacity, 3.0 L (97\% of the predicted value); forced expiratory volume in one second (FEV1) $2.8 \mathrm{~L}$ (109\% pred); and provocative dose of methacholine causing a $20 \%$ fall in FEV1 $347 \mu \mathrm{g}$.

The patient had had a history of allergic asthma and rhinitis since 1992. Aspirin sensitivity was also present. Skin-prick tests for common (grass pollens and cat) and occupational allergens (flour and mites) gave positive results, methacholine inhalation challenge showed severe airway hyperresponsiveness (PD20 $70 \mu \mathrm{g}$ ) and peak expiratory flow rates (PEFRs) were in the range 400-460 $\mathrm{L} \cdot \mathrm{min}^{-1}$ with low diurnal variation. The medications she received were inhaled glucocorticoids, salbutamol and longacting $\beta$-adrenergic agonists. Despite this treatment, she had had three severe asthma attacks after exposure to flour in the workplace, which required admission to the hospital. She was treated with courses of oral glucocorticoids. In 1997, she stopped working as a cook and was hired as a cleaner in a chain of cafeterias. Her PEFRs were in the range $340-480 \mathrm{~L} \cdot \mathrm{min}^{-1}$ and the diurnal variation was $>20 \%$. In the months preceding the exposure to chlorine, her asthma was well controlled by therapy with low doses of budesonide $\left(200 \mu \mathrm{g} \cdot \mathrm{day}^{-1}\right)$ and salbutamol was taken seldom or never. PEFRs were in the range of $450-510 \mathrm{~L} \cdot \mathrm{min}^{-1}$ and lung volumes were normal (FEV1 101\% pred).

\section{Discussion}

The clinical picture of this patient indicates immediate onset of a severe asthmatic attack and delayed onset of adults respiratory distress syndrome (ARDS) after inhalation of chlorine vapours.

The dose of a toxic exposure which reaches the respiratory tree depends on a complex mixture of host, agent and environmental factors. This case emphasizes the importance of the question as to why asthmatic airways show a tendency to become more easily obstructed in response to different stimuli, and whether this mechanism protects the lower airways or whether it may be overwhelmed in some circumstances.

An increasing number of substances with irritant, sensitizing or toxic properties can be found in the workplace [2] and in housework. Examples of inhaled chemicals known to cause pulmonary oedema include nitrogen dioxide, chlorine, sulphur dioxide, ammonia and smoke $[3,4]$. Chlorine gas, used extensively as a chemical weapon in Europe during the First World War, is a common inhaled irritant both occupationally and environmentally [5-8]. Irritant exposure induces a variety of responses including ARDS and irritant-induced asthma [9]. Irritant exposure and chlorine inhalation have been considered a frequent cause of irritant-induced asthma (reactive airways dysfunction syndrome (RADS)) [10], but, following irritant exposure, some subjects do not develop symptoms consistent with RADS [11, 12]. D'AlesSANDRo et al. [13] have shown that persons with hyperreactive airways manifest an exaggerated airway response to chlorine at 1.0 part per million. Moreover, the present study indicates that chlorine is the only environmental irritant studied, other than sulphur dioxide, to which asthmatics as a group may be predictably hyperresponsive. Reliable information regarding the frequency of acute inhalation accidents at work is scarce. The importance of chlorine exposures has been emphasized both in Europe [14] and the USA [15]. In the US annual report for 1998, there were 214 accidents treated at healthcare facilities following mixing of hypochlorite with acids, of which one was severe.

Exposure within a confined and poorly ventilated space should raise the possibility of inhalation injury, and this case report supports this hypothesis. Conversely, factors related to the host, in this case, the presence of pre-existing asthma and of hyperreactive airways may modulate the response to the offending agent [16] and, according to previous studies [13], the severe airway hyperreactivity of the patient here described might have been a risk factor tor illness severity. The clinical picture, symptoms, i.e. tachypnoea, radiographic features, severe hypoxaemia with an $\mathrm{Pa}_{\mathrm{a}} \mathrm{O}_{2} / F \mathrm{I}, \mathrm{O}_{2}$ ratio of $<150$ and low CVP observed 
in the first days in the ICU meet the criteria for ARDS. In this patient, assist-control ventilation and weaning were difficult since two components were present: increased airway resistance and decreased lung compliance. However, at variance with most reported studies of a poor prognosis of increased permeability pulmonary oedema, with some $50-60 \%$ of patients dying [17], the prognosis here was good without important sequelae. This could be due to the fact that, in this patient, the underlying cause was self-limiting, i.e. short-term exposure to chlorine, there was a good response to treatment and serious underlying disease, especially sepsis, was absent.

In a prospective interview-based follow-up study of inhalation cases, BLANC et al. [12] found that mixing hypochlorite bleach with products such as ammonia or acids was the second most common cause of exposure among nonoccupational cases. Such exposures also occurred among the occupational cases. The present study also showed that host-related factors such as pre-existing lung disease were associated with significantly increased risk of illness severity.

Based on this experience and prior literature, it is necessary to identify the populations at risk of inhalation injury (both occupationally and environmentally) to avoid such accidents and to evaluate potential predisposing factors (persons with increased baseline airway responsiveness to nonspecific stimuli) with the aim of reducing severity and avoiding permanent functional impairment.

\footnotetext{
Acknowledgements. The authors would like to thank the patient who gave consent to publish her clinical history. G. Fulgeri for typing the manuscript and C. Drace for revising the manuscript.
}

\section{References}

1. Centers for Disease Control. Chlorine gas toxicity from mixture of bleach with other cleaning products-California. MMWR Morb Mortal Wkly Rep 1991; 40: 619621, 627-629.

2. Blanc PD, Schwartz DA. Acute pulmonary responses to toxic exposures. In: Murray JF, Nadel JA, eds. Respiratory Medicine. 2nd Edn. Philadelphia, PA, W.B. Saunders Company, 1994; pp. 2050-2061.

3. Smith RS, Spragg RG. The lung in the intensive care unit.
In: Crystal RG, West JB, eds. The Lung, Scientific Foundations. New York, NY, Raven Press Ltd, 1991; pp. 2185-2196.

4. Sheppard D. Chemical agents. In: Murray JF, Nadel JA, eds. Textbook of Respiratory Medicine, Philadelphia, PA, W.B. Saunders Company, 1988, pp. 1631-1647.

5. Das R, Blanc PD. Chlorine gas exposure and the lung. Toxicol Ind Health 1993; 9: 439-455.

6. Gaurin D, Leroyer C, Infante-Rivard C, et al. Longitudinal assessment of airway caliber and responsiveness in workers exposed to chlorine. Am J Respir Crit Care Med 1999; 160: 1232-1237.

7. Weill H, George R, Schwarz M, Ziskind M. Late evaluation of pulmonary function after acute exposure to chlorine gas. Am Rev Respir Dis 1969; 99: 374-379.

8. Kennedy SM. Acquired airway hyperresponsiveness from nonimmunogenic irritant exposure. Occup Med 1992; 7: 287-300.

9. Boulet L-P, Bowie D. Acute occupational respiratory disease. Eur Respir Mon 1999; 11: 320-346.

10. Donnelly SC, FitzGerald MX. Reactive airways dysfunction syndrome (RADS) due to chlorine gas exposure. Ir J Med Sci 1990; 159: 275-277.

11. Blanc PD, Galbo M, Hiatt P, et al. Symptoms, lung function and airway hyperresponsiveness following irritant inhalation. Chest 1993; 103: 1699-1705.

12. Blanc PD, Galbo M, Hiatt P, Olson KR. Morbidity following-acute irritant inhalation in a population-based study. JAMA 1991; 266: 664-669.

13. D'Alessandro A, Kuschner W, Wong H, Boushey HA, Blanc PD. Exaggerated responses to chlorine inhalation among persons with nonspecific airway hyperreactivity. Chest 1996; 109: 331-337.

14. Meyer JD, Holt DL, Cherry NM, McDonald JC. SWORD 1998: Surveillance of work-related and occupational respiratory disease in the UK. Occup Med 1999; 49: 485489.

15. Litovitz TL, Klein-Schwartz W, Caravati EM, et al. 1998 Annual Report of the American Association of Poison Control Centers Toxic Exposure Surveillance System. Am J Emerg Med 1999; 17: 435-487.

16. Clarke S. Respiratory defences, physical defences. In: Brewis RAL, Corin B, Geddes DM, Gibson GJ, eds. Respiratory Medicine. 2nd Edn. Philadelphia, PA, W.B. Saunders Company, 1994, pp. 179-191.

17. Wang J, Oppennheimer L, Fata $\mathrm{P}$, et al. Spectroscopic approach to capillary-alveolar membrane damage induced acute lung injury. Can Respir J 1999; 6: 499-506. 